\title{
Characterizing Aciniform Silk Repetitive Domain Backbone Dynamics and Hydrodynamic Modularity
}

\author{
Marie-Laurence Tremblay ${ }^{1}$, Lingling Xu ${ }^{1}$, Muzaddid Sarker ${ }^{1}$, Xiang-Qin Liu ${ }^{1}$ \\ and Jan K. Rainey ${ }^{1,2, *}$ \\ 1 Department of Biochemistry \& Molecular Biology, Dalhousie University, Halifax, NS B3H 4R2, Canada; \\ mltremblay@dal.ca (M.-L.T.); ln217415@dal.ca (L.X.); muzaddid.sarker@dal.ca (M.S.); \\ paul.liu@dal.ca (X.-Q.L.) \\ 2 Department of Chemistry, Dalhousie University, Halifax, NS B3H 4R2, Canada \\ * Correspondence: jan.rainey@dal.ca; Tel.: +1-902-494-4632
}

Academic Editor: John G. Hardy

Received: 29 June 2016; Accepted: 4 August 2016; Published: 10 August 2016

\begin{abstract}
Spider aciniform (wrapping) silk is a remarkable fibrillar biomaterial with outstanding mechanical properties. It is a modular protein consisting, in Argiope trifasciata, of a core repetitive domain of 200 amino acid units ( $\mathrm{W}$ units). In solution, the $\mathrm{W}$ units comprise a globular folded core, with five $\alpha$-helices, and disordered tails that are linked to form a 63-residue intrinsically disordered linker in concatemers. Herein, we present nuclear magnetic resonance (NMR) spectroscopy-based ${ }^{15} \mathrm{~N}$ spin relaxation analysis, allowing characterization of backbone dynamics as a function of residue on the ps-ns timescale in the context of the single $\mathrm{W}$ unit $\left(\mathrm{W}_{1}\right)$ and the two unit concatemer $\left(\mathrm{W}_{2}\right)$. Unambiguous mapping of backbone dynamics throughout $\mathrm{W}_{2}$ was made possible by segmental NMR active isotope-enrichment through split intein-mediated trans-splicing. Spectral density mapping for $W_{1}$ and $W_{2}$ reveals a striking disparity in dynamics between the folded core and the disordered linker and tail regions. These data are also consistent with rotational diffusion behaviour where each globular domain tumbles almost independently of its neighbour. At a localized level, helix 5 exhibits elevated high frequency dynamics relative to the proximal helix 4 , supporting a model of fibrillogenesis where this helix unfolds as part of the transition to a mixed $\alpha$-helix/ $\beta$-sheet fibre.
\end{abstract}

Keywords: aciniform spidroin (AcSp1); wrapping silk; recombinant spider silk; modular proteins; reduced spectral density mapping; hydrodynamics characterization; nuclear magnetic resonance spectroscopy; split intein; segmental-labelling

\section{Introduction}

Spider aciniform (or wrapping) silk is the toughest type of silk and is a remarkable biomaterial with outstanding mechanical properties [1]. Spider silk proteins (spidroins) and silkworm silk proteins (fibroins) share a general architecture of a relatively long repetitive domain, comprising a concatenated series of repetitive units or sequence motifs, flanked by much shorter non-repetitive $\mathrm{N}$ - and C-terminal domains [2,3]. Aciniform spidroin (AcSp1) is the primary constituent of wrapping silk. In Argiope trifasciata, it is a modular protein containing at least 14 identical concatenated repeats of a 200 amino acid unit (termed here "W" units, from wrapping) [4].

Modular protein architecture, in which discrete structured modules are connected together by linkers that range from rigid to highly flexible, is common in nature [5-7]. The structure of individual domains are frequently studied in isolation by nuclear magnetic resonance (NMR) spectroscopy and/or X-ray diffraction, then placed in a multi-domain context through NMR spectroscopy [8,9], small angle X-ray scattering [10], or cryo-electron microscopy [11], allowing delineation of structure and dynamics in the context of the larger assembly. The orientation of domains relative to one another, 
their dynamics, and the relation between domains is crucial for expanding our understanding of their function $[9,12,13]$.

Many multi-domain proteins comprise discrete, differing units (e.g., scaffolding units such as the SH2, SH3, PDZ, or PTB domains) connected by linkers with both widespread pathophysiological consequences [14] and potential for recombination for synthetic biology purposes [15]. From an NMR spectroscopy standpoint, di-ubiquitin $[16,17]$ and GB1 [18] have been extensively studied as model multi-domain proteins. In contrast to these proteins, where discrete modules impart individual function, many fibrous proteins including spider silks employ repetitive modules [2]. This adds unique difficulties for structural biology, where the repetitive nature of these proteins leads to challenges in unambiguously tracking individual modules.

We recently employed NMR spectroscopy to determine the solution-state structure of the recombinant $\mathrm{W}$ unit of $A$. trifasciata $\mathrm{AcSp} 1$ in the context of both the single unit $\left(\mathrm{W}_{1}\right)$ and the two-unit concatemer $\left(W_{2}\right)$ [19]. $W_{1}$ is composed of a predominantly helical globular domain composed of five defined $\alpha$-helices with an unstructured $\sim 12$ residue $\mathrm{N}$-terminal tail and $\sim 50$ residue $\mathrm{C}$-terminal tail. In $W_{2}$, the tails of neighbouring units become a linker that retains intrinsically disordered behaviour while the globular domains are identically structured giving rise to beads-on-a-string type conformation.

Fibres cannot be formed from solutions of $\mathrm{W}_{1}$, but manual drawing of fibres is readily possible from solutions containing $\mathrm{W}_{2}, \mathrm{~W}_{3}$, or $\mathrm{W}_{4}$ concatemers [20], including from solution-state NMR samples of $W_{2}$ [19]. During fibre formation, AcSp1 undergoes a partial conversion from $\alpha$-helical to $\beta$-sheet structuring [21], putatively seeded at helix 5 in the $W$ unit $[19,22]$. This transition is recapitulated in recombinant $W_{2}$ between the soluble and fibrous forms [19]. The 200 residue $W$ unit from A. trifasciata differs significantly from other spider silks, such as the extensively studied major and minor ampullate silks, where short repetitive motifs such as $A_{n},(G A)_{n}$, GGX or GPGXX dominate the protein sequence [1,2]. Silkworm fibroin is also dominated by short motifs (e.g., GAGAGS and GAGAGY) in its repetitive domain $[3,23]$. Echoing these differences in primary structuring, the retention of $\alpha$-helical character in aciniform silk fibre is distinct from both ampullate silks and silkworm silk, where fibres are completely depleted of $\alpha$-helical character $[1,2,21]$. Hence, although recombinant $\mathrm{W}$ proteins are much shorter than native aciniform silk proteins and lack non-repetitive $\mathrm{N}$ - and C-terminal domains, with reduced strength and extensibility relative to native silk that scale approximately with the number of $\mathrm{W}$ units [24], the structural behaviour of these proteins is consistent with the native protein.

Characterization of dynamics within proteins at the atomic-level is possible at a variety of time-scales using NMR spectroscopy $[25,26]$. Measurement of ${ }^{15} \mathrm{~N}$ nuclear spin relaxation properties, namely the longitudinal and transverse relaxation times ( $T_{1}$ and $T_{2}$, respectively) and cross-relaxation through the heteronuclear ${ }^{1} \mathrm{H}_{-}{ }^{15} \mathrm{~N}$ nuclear Overhauser effect $\left(\left[{ }^{1} \mathrm{H}\right]-{ }^{15} \mathrm{~N}\right.$ NOE$)$ in particular, allow for characterization of small-amplitude, high-frequency motions as a function of position along the polypeptide backbone together with delineation of regions experiencing slower dynamic fluctuations [27]. Relation of these spin relaxation parameters to global and local motion is often carried out through the model-free [28] or extended model-free [29] approaches. In instances where a single global correlation time is not suitable, such as for proteins containing large unstructured regions, the reduced spectral density mapping approach provides residue-by-residue characterization of dynamics without a reliance on global rotational diffusion parameters [30].

These dynamics characterization methods rely upon unambiguous distinction of ${ }^{1} \mathrm{H}_{-}{ }^{15} \mathrm{~N}$ cross-peaks in 2D spectra, a situation impossible in concatemeric AcSp1 repeat units without some means to distinguish one $\mathrm{W}$ unit from the other. The technique of intein-mediated trans-splicing provides such a means, where individual $W_{1}$ units can be selectively labelled with NMR active isotopes and investigated, in the present work, in the context of the larger fibre-forming $\mathrm{W}_{2}$ protein. Inteins are naturally-occurring protein segments that excise themselves from a polypeptide and ligate the flanking protein segments together with a native peptide bond. This reaction will occur provided 
that a nucleophilic Ser or Cys is present immediately C-terminal to the intein and that the intein-protein fragment pair are stable in solution and allow the ligation to occur [31,32].

There have now been many demonstrated applications of inteins in structural biology and biotechnology [32,33], including protein cyclization [34-36]; protein switches [37-40]; in vivo protein engineering and probe attachment for biophysical studies [41-43]; and, importantly for the present work, segmental isotope enrichment [19,31,44-48]. In our previous structural studies [19], we performed segmental-labelling using split intein trans-splicing [49,50], whereby either the first $\left(\mathrm{W}_{2-1}\right)$ or second $\left(\mathrm{W}_{2-2}\right) \mathrm{W}$ unit in $\mathrm{W}_{2}$ was enriched with NMR-active ${ }^{13} \mathrm{C}$ and $/$ or ${ }^{15} \mathrm{~N}$ nuclei while the other $\mathrm{W}$ unit was at natural abundance. Although we demonstrated differential dynamics between the globular core and linker/tail regions through variation in the observed heteronuclear $\left[{ }^{1} \mathrm{H}\right]-{ }^{15} \mathrm{~N} N O E$, a more in-depth analysis of backbone dynamics is necessary to compare and contrast the behaviour of isolated $\mathrm{W}$ units vs. concatemers and to provide insight into more subtle variations in dynamics within the $\mathrm{W}$ unit.

Herein, new insight has been gained into the modularity, global conformation, and localized backbone dynamics behaviour of spider wrapping silk concatemers through characterization of ps-ns timescale NMR relaxation behaviour of each $W$ unit in $W_{2}$ relative to one another and to $W_{1}$. In $W_{1}$ and in each $W$ unit of $W_{2}$, reduced spectral density mapping is consistent with a structured five $\alpha$-helix globular core having elevated dynamics in helix 5 with intrinsically disordered $\mathrm{N}$ - and C-terminal tails and, in $\mathrm{W}_{2}$, linker. Nuclear spin relaxation data are consistent with rotational diffusion by a compact globular core in $W_{1}$ and with modular tumbling of each $W$ unit in $W_{2}$ almost independently of the remainder of the protein. Beyond ramifications for $\mathrm{AcSp} 1$ behaviour, the methods presented herein will serve as a useful atomic-level model for further characterization of modular proteins in solution.

\section{Results}

\subsection{Nuclear Spin Relaxation Parameters}

Longitudinal $\left(T_{1}\right)$ and transverse $\left(T_{2}\right)$ relaxation time constants were measured at $16.4 \mathrm{~T}$ on a residue-by-residue basis [27] for both the monomeric $\left(\mathrm{W}_{1}\right)$ and concatemeric $\left(\mathrm{W}_{2}\right)$ states of recombinant AcSp1 (Figure 1). To facilitate direct comparison, and because these data are integral for the subsequent analysis, the $\left[{ }^{1} \mathrm{H}\right]-{ }^{15} \mathrm{~N}$ data that we previously reported [19] are also plotted in Figure 1. A segregation in spin relaxation behaviour is clear between (i) the folded domain (residues 12-149 for a given W unit, with secondary structure elements shown in linear form in Figure 1) and (ii) the N- and C-terminal tails of $W_{1}$ and $W_{2}$ and the linker spanning $W_{2-1}$ to $W_{2-2}$ in $W_{2}$. Namely, $T_{1}$ and the $\left[{ }^{1} \mathrm{H}\right]{ }^{15} \mathrm{~N}$ NOE are elevated through the folded core of a given $\mathrm{W}$ unit and decrease in the linker and tail regions while $T_{2}$ exhibits the opposite trend.

For direct overall comparison, mean values of $T_{1}$ and $T_{2}$ were determined for four subdivided regions of the $\mathrm{W}$ unit chosen based upon our previous structural and ${ }^{19} \mathrm{~F}-\mathrm{NMR}$ studies: the globular core (residues 12-149 and, in $W_{2}, 212-349$ ), helix 5 within the core (residues 135-149 and, in $W_{2}$, 335-349), tails ( $\mathrm{W}_{1}$ : residues $1-11$ and 150-199; $\mathrm{W}_{2}$ : residues $1-11$ and 350-400), and the linker (residues 150-211 in $W_{2}$ only) (Figure 2). Qualitatively, $T_{1}$ is larger while $T_{2}$ is smaller in the globular core for each $W_{2}$ subunit relative to $W_{1}$. The observed behaviour is consistent with the ${ }^{15} \mathrm{~N}$ relaxation behaviour to be expected on the basis of more rapidly $\left(\mathrm{W}_{1}\right)$ vs. slowly $\left(\mathrm{W}_{2}\right)$ tumbling molecules [27]. Notably, $T_{1}$ values for $W_{1}, W_{2-1}$, and $W_{2-2}$ are significantly different for the core ( $p$-value $\left.<0.0001\right)$ and helix 5 ( $p$-value $<0.01$ ), while the tails are relatively similar (albeit with large variance) regardless of protein size.

In examining overall $T_{2}$ behaviour (Figure 2), the most striking feature is the large difference in mean values between the globular core and the disordered tails/linker, with a significant elevation in $T_{2}$ for the tails or linker in all $\mathrm{W}$ units. As with $T_{1}, \mathrm{~W}_{1}$ exhibits a significant difference in behaviour from both $W_{2-1}$ and $W_{2-2}(p$-value $<0.0001)$, with an elevated $T_{2}$ relative to either unit in $W_{2}$. Although the significance is low $(p$-value $<0.1)$, helix 5 follows the same qualitative trend. Unlike with $T_{1}$, 
however, $W_{2-1}$ and $W_{2-2}$ do not exhibit significant differences in $T_{2}$ relative to each other. Although the tails would be expected to be less encumbered and more dynamic overall, there is no difference between the mean values observed for the tails and the linker.
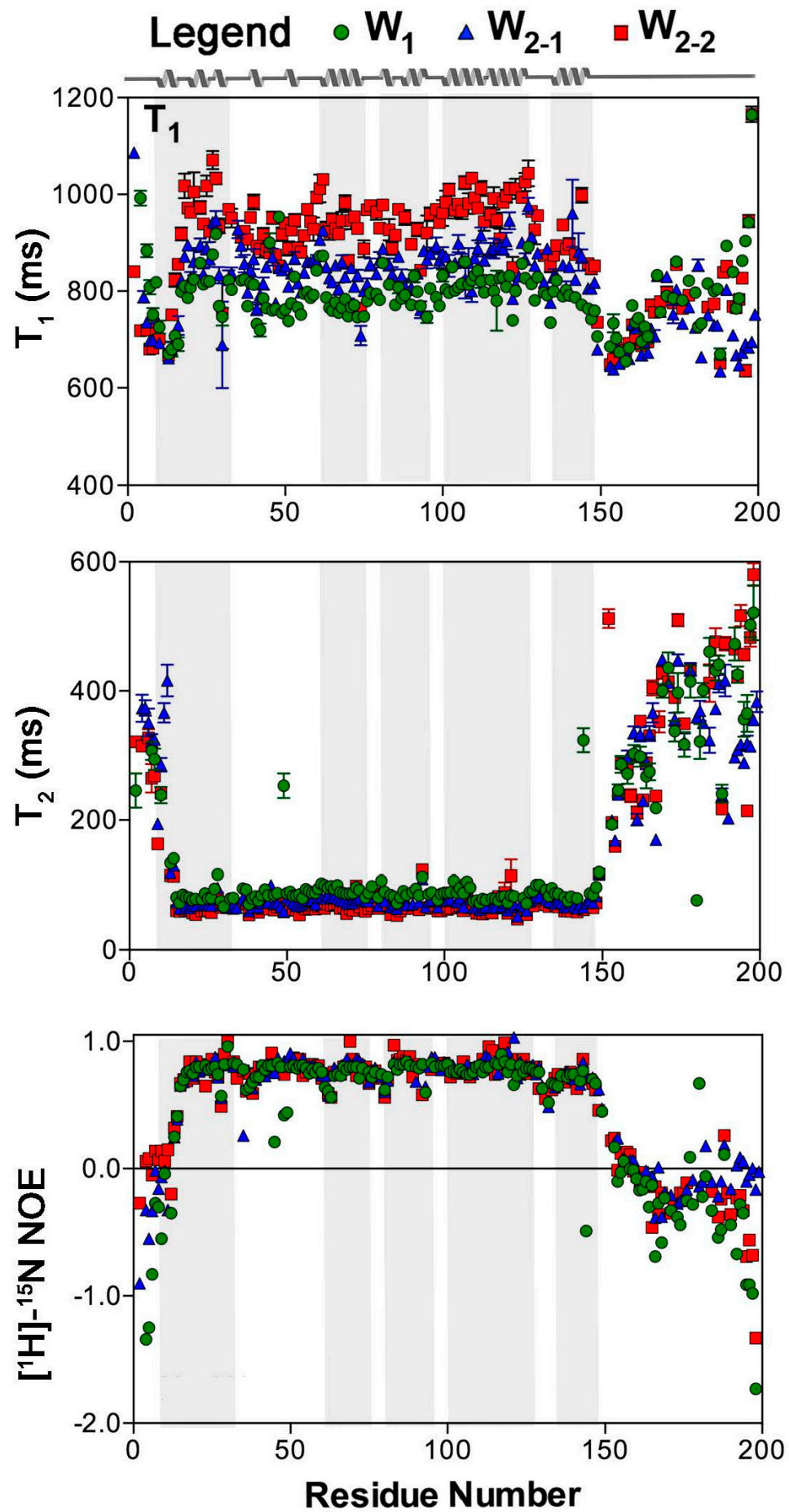

Figure 1. ${ }^{15} \mathrm{~N}$ spin relaxation parameters as a function of residue at $16.4 \mathrm{~T}$ for $\mathrm{W}_{1}, \mathrm{~W}_{2-1}$, and $W_{2-2}$. Analysis and error propagation were carried out using Mathematica notebooks from Leo Spyracopoulos [51]. The secondary structuring of the $\mathrm{W}$ unit is depicted on the basis of PDB entry 2MU3 [19], with grey shading for each helical segment. 

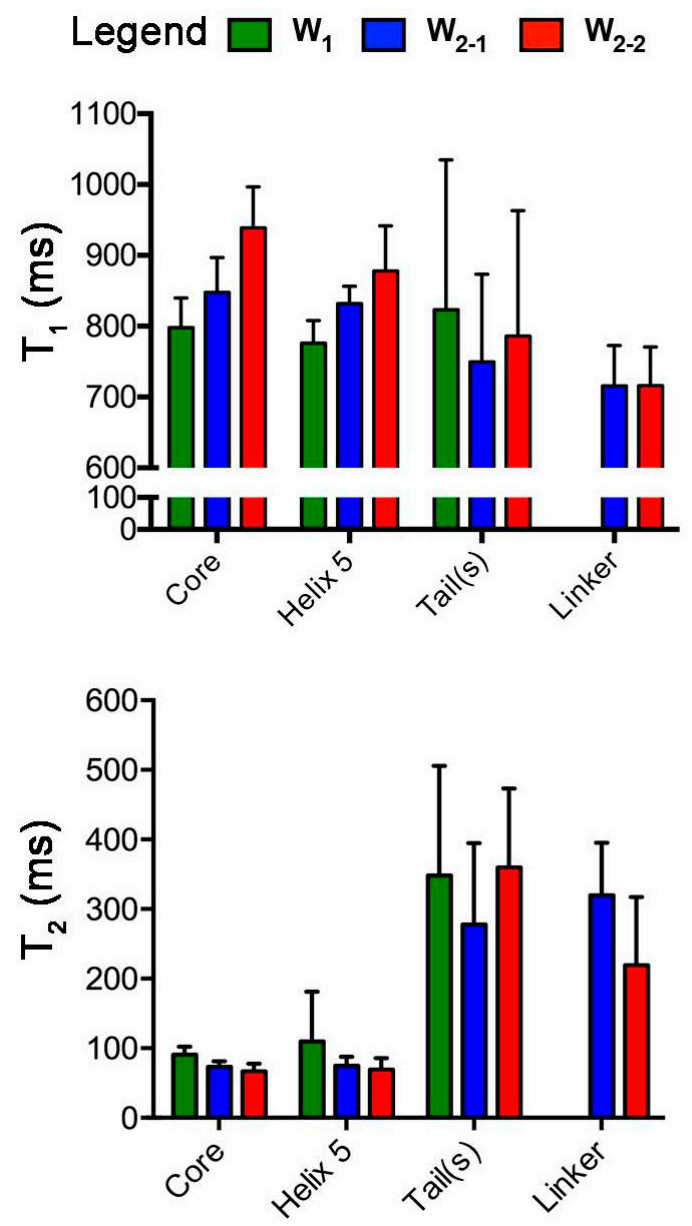

Figure 2. Bar graphs representing the mean $T_{1}$ and $T_{2}$ (error bars: standard deviations) for key regions of the $W$ unit. These were specifically defined as the core (residues 12-149 $\left(\mathrm{W}_{1}, \mathrm{~W}_{2-1}\right)$ and 212-349 $\left(W_{2-2}\right)$ ), linker (residues $150-211$ from $W_{2-1}$ and $\left.W_{2-2}\right)$, tails $\left(W_{1}\right.$ : residues 1-11 and 150-199; $\mathrm{W}_{2}$ : residues 1-11 and 350-400), and helix 5 (residues $135-149\left(\mathrm{~W}_{1}, \mathrm{~W}_{2-1}\right)$ and 335-349 $\left(\mathrm{W}_{2-2}\right)$ ).

\subsection{Reduced Spectral Density Mapping}

The values of the reduced spectral density at $J(0), J\left(\omega_{\mathrm{N}}\right)$, and $J\left(0.87 \omega_{\mathrm{H}}\right)$ were calculated independently for each $W$ unit. All residues with $T_{1}$ and $T_{2}$ fits that met the goodness-of-fit criterion $\left(\chi^{2}<\right.$ critical $\chi^{2}$ [51]) for a given dataset at $16.4 \mathrm{~T}$ were employed for spectral density determination, giving 145,153 , and 131 residues, respectively, for $W_{1}, W_{2-1}$, and $W_{2-2} . J\left(0.87 \omega_{H}\right)$ and $J(0)$ both strongly demonstrate disparate dynamics between the folded core and the tails/linker, mirroring the behaviour of the individual $T_{1}, T_{2}$, and $\left[{ }^{1} \mathrm{H}\right]-{ }^{15} \mathrm{~N}$ NOE parameters (Figures 3 and 4 ). $J\left(\omega_{\mathrm{N}}\right)$, conversely, remains relatively uniform throughout all regions of a given unit of $W_{1}$ or $W_{2}$, without significant differences between globular and linker domains. Reflecting the relatively strong dependence of $J\left(\omega_{N}\right)$ on $T_{1}$, an expected decrease in $J\left(\omega_{N}\right)$ is observed from $W_{1}, W_{2-1}$, to $W_{2-2}$ for the globular core ( $p$-value $<0.0001)$, with helix 5 following suit ( $p$-value $<0.01)$, while those for the tails and linker are not significantly different between the $\mathrm{W}$ units.

$J\left(0.87 \omega_{\mathrm{H}}\right)$, which is very sensitive to differences in motion in the high frequency regime [52], exhibits localized increases in $W_{1}$ and in each $W$ unit of $W_{2}$ around residues $36,63,80,121$, and 132 (Figure 3), correlating directly to the locations of loops or turns within the $W$ unit [19]. It should be noted, though, that the increases in $J\left(0.87 \omega_{\mathrm{H}}\right)$ observed at these locations are not of the same magnitude as those seen for the linker or tails (Figure 3). These variations are, therefore, likely reflective of regions of the protein experiencing increased dynamics but tumbling with the core of the folded domain rather than behaving as intrinsically-disordered segments. 

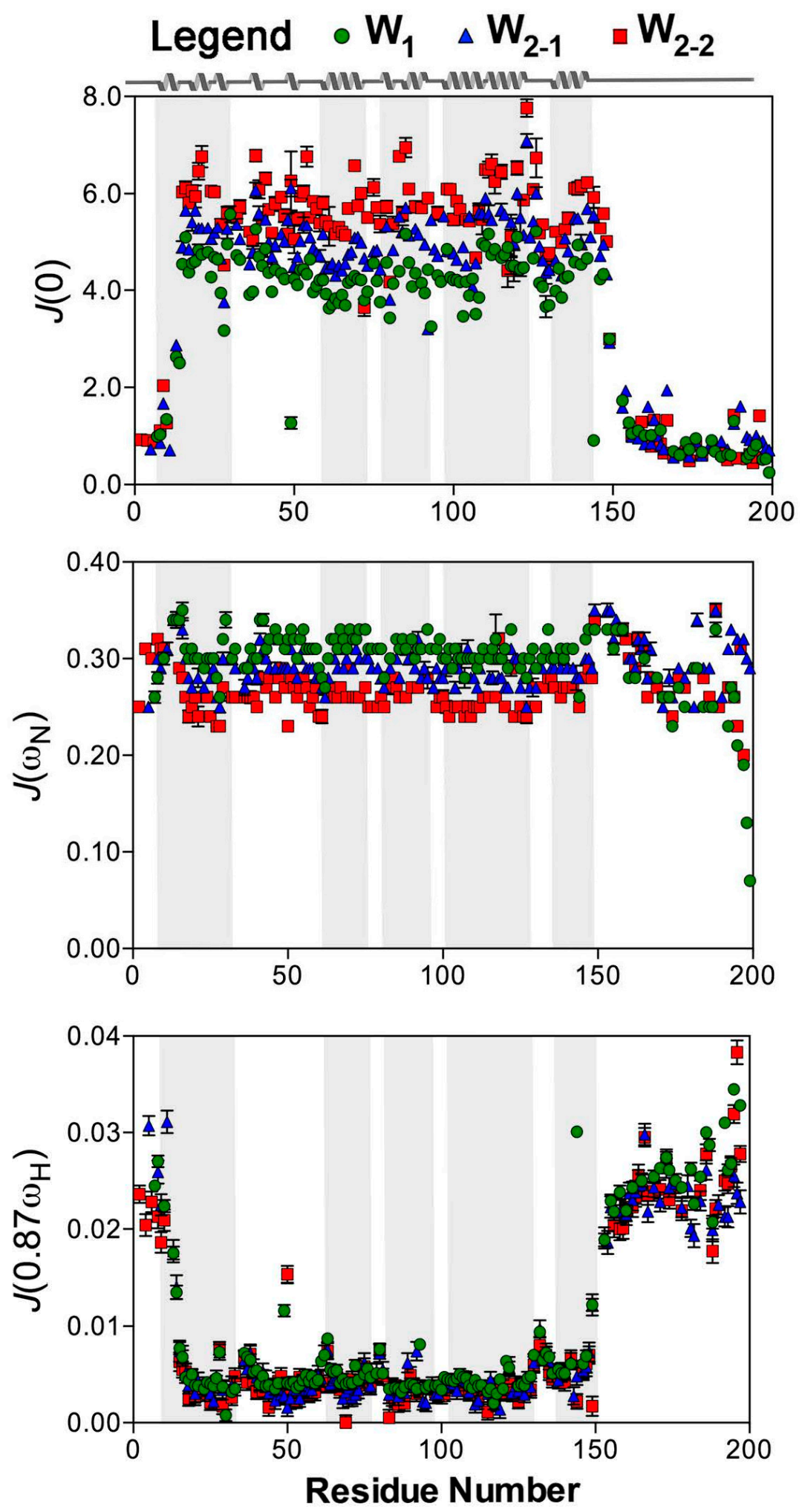

Figure $3 .{ }^{15} \mathrm{~N}$ reduced spectral density mapping [30] at $16.4 \mathrm{~T}$ as a function of residue for $\mathrm{W}_{1}, \mathrm{~W}_{2-1}$, and $\mathrm{W}_{2-2}$. Analysis and error propagation were carried out using Mathematica notebooks from Leo Spyracopoulos [51]. 


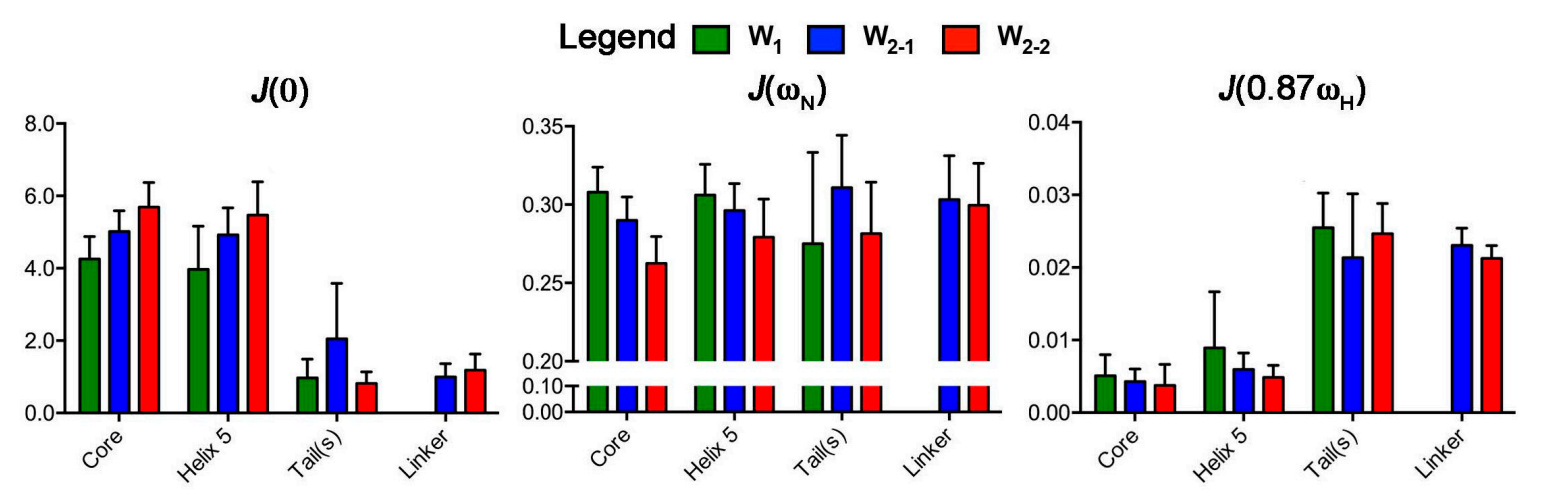

Figure 4. Bar graphs representing the mean $J(0), J\left(\omega_{\mathrm{N}}\right)$, and $J\left(0.87 \omega_{\mathrm{H}}\right)$ (error bars: standard deviation) over key $\mathrm{W}$ unit regions. These were specifically defined as the core (residues 12-149 $\left(\mathrm{W}_{1}, \mathrm{~W}_{2-1}\right)$ and 212-349 $\left(\mathrm{W}_{2-2}\right)$ ), linker (residues $150-211$ from $W_{2-1}$ and $\left.W_{2-2}\right)$, tails $\left(W_{1}\right.$ : residues 1-11 and 150-199; $\mathrm{W}_{2}$ : residues 1-11 and 350-400), and helix 5 (residues $135-149\left(\mathrm{~W}_{1}, \mathrm{~W}_{2-1}\right)$ and 335-349 $\left(\mathrm{W}_{2-2}\right)$ ).

A statistically significant increase in $J\left(0.87 \omega_{\mathrm{H}}\right)$ is also observed for helix 5 (residues 135-149) relative to helix 4 (residues 101-127) ( $p$-values of $0.0060,0.0001$, and 0.0025 for $\mathrm{W}_{1}, \mathrm{~W}_{2-1}$, and $\mathrm{W}_{2-2}$, respectively) or to the core (helices 1-4) ( $p$-values of $0.019,0.0011$, and 0.0085 for $\mathrm{W}_{1}, \mathrm{~W}_{2-1}$, and $\mathrm{W}_{2-2}$, respectively). Helix 1, like helix 5, is directly connected to a disordered tail or linker segment [19]; therefore, helix 1 would be expected to exhibit similarly elevated dynamics if proximity to a tail or linker were the only factor at play. Instead, helix 1 behaves more like a core helix, as demonstrated by a lack of significant differences in $J\left(0.87 \omega_{\mathrm{H}}\right)$ for helix 1 vs. helix 4 ( $p$-values of $0.11,0.046$, and 0.126 for $\mathrm{W}_{1}, \mathrm{~W}_{2-1}$, and $\mathrm{W}_{2-2}$, respectively). There is also a qualitative difference between $J\left(0.87 \omega_{\mathrm{H}}\right)$ of helix 5 in the $\mathrm{W}$ units, with $\mathrm{W}_{1}>\mathrm{W}_{2-1}>\mathrm{W}_{2-2}$ (Figure 4) following the same qualitative trend as the core as a whole.

Like $J\left(\omega_{N}\right)$, the behaviour at $J(0)$ differs between $W_{1}, W_{2-1}$, and $W_{2-2}$ in the globular core ( $p$-value $<0.0001$ ) and helix 5 ( $p$-value $<0.001$ ), increasing from $W_{1}$, to $W_{2-1}$ and $W_{2-2}$ and opposite in trend to the observed decrease in $J\left(\omega_{N}\right)$. $W_{1}$ has the lowest mean frequency at $J(0)$ over the folded core $(4.26 \pm 0.07)$, followed by $W_{2-1}(5.02 \pm 0.11)$, and then $W_{2-2}(5.67 \pm 0.37)$ (Figure 4). On average, the tail/linker regions do differ between $W_{1}, W_{2-1}$, and $W_{2-2}$ but care must be taken during interpretation given that the tail group for $\mathrm{W}_{2-1}$ has seven values and $\mathrm{W}_{2-2}$ linker has six values. When the tails and linker are grouped together, there is no statistical difference between the $\mathrm{W}$ units.

\subsection{Analysis of Rotational Diffusion}

Spin relaxation data were used to compare the suitability of isotropic, axially symmetric, or fully anisotropic rotational diffusion tensors for $\mathrm{W}_{1}, \mathrm{~W}_{2-1}, \mathrm{~W}_{2-2}$, and $\mathrm{W}_{2}$ based upon all residues with $\left[{ }^{1} \mathrm{H}\right]-{ }^{15} \mathrm{~N}$ NOE $>0.65$ [53] using the software ROTDIF [54]. In each instance, an axially symmetric rotational diffusion tensor provided the best fit to the data (Table 1); notably, the degree of anisotropy observed was minimal in light of the fact that $~ 90 \%$ of an 878 monomeric protein dataset exhibited an anisotropy of 1.17 or higher [54]. $\mathrm{W}_{1}$ spin relaxation data were best fit with a prolate rotational diffusion tensor for all 20 members of the NMR structural ensemble (PDB entry 2MU3 [19]), with an anisotropy range of 1.09-1.18. Conversely, $\mathrm{W}_{2-2}$ was uniformly oblate (anisotropy 0.90-0.95 with $\mathrm{W}_{1}$ ensemble) while $\mathrm{W}_{2-1}$ varied depending upon the ensemble member employed, with anisotropy of 1.05-1.16 (16 members) or 0.88-0.95 (four members) observed. The fitting behaviour for $\mathrm{W}_{2-1}$ is consistent with the small degree of anisotropy observed, with minimal deviation from an isotropic fit. Additionally, diffusion tensors were modelled for a combined $W_{2-1}$ and $W_{2-2}$ spin relaxation data set using the ensemble of 20 inferred $W_{2}$ structures [19]. In this instance, anisotropy remained minimal and most ensemble members led to oblate fits (anisotropy 0.8-0.92 for 18 members; $1.12-1.13$ for two members). Goodness-of-fit, as judged by $\chi^{2}$ per degrees of freedom, was comparable in all instances (Table 1). 
Table 1. Rotational diffusion tensor parameters that best fit indicated ${ }^{15} \mathrm{~N}$ spin relaxation data set.

\begin{tabular}{|c|c|c|c|c|c|c|c|c|}
\hline Protein ${ }^{1}$ & $\begin{array}{c}\mathrm{N}-\mathrm{H} \\
\text { Bonds }{ }^{2}\end{array}$ & $\begin{array}{c}D_{\perp} \\
\left(\times 10^{-7} s^{-1}\right)\end{array}$ & $\begin{array}{c}D_{||} \\
\left(\times \mathbf{1 0}^{-7} \mathrm{~s}^{-\mathbf{1}}\right)\end{array}$ & Anisotropy & $\alpha\left({ }^{\circ}\right)$ & $\beta\left({ }^{\circ}\right)$ & $\tau_{\mathrm{c}}(\mathrm{ns})$ & $\chi^{2} / \mathrm{df}^{3}$ \\
\hline $\mathrm{W}_{1}$ & 102 & $2.01 \pm 0.05$ & $2.30 \pm 0.08$ & $1.14 \pm 0.17$ & $13 \pm 52$ & $43 \pm 19$ & $7.91 \pm 0.03$ & 1.409 \\
\hline $\mathrm{W}_{2-1}$ & 104 & $1.82 \pm 0.07$ & $1.93 \pm 0.04$ & $1.06 \pm 0.13$ & $164 \pm 87$ & $138 \pm 20$ & $8.98 \pm 0.03$ & 1.889 \\
\hline $\mathrm{W}_{2-2}$ & 93 & $1.78 \pm 0.03$ & $1.63 \pm 0.03$ & $0.92 \pm 0.09$ & $77 \pm 37$ & $155 \pm 10$ & $9.65 \pm 0.04$ & 1.906 \\
\hline $\mathrm{W}_{2}$ & 197 & $1.87 \pm 0.04$ & $1.68 \pm 0.04$ & $0.90 \pm 0.11$ & $26 \pm 31$ & $20 \pm 22$ & $9.24 \pm 0.05$ & 2.309 \\
\hline
\end{tabular}

${ }^{1}$ Diffusion tensor detailed for lowest-energy member of the $W_{1}$ structural ensemble (PDB entry 2MU3 [19]) for $\mathrm{W}_{1}, \mathrm{~W}_{2-1}$, and $\mathrm{W}_{2-2}$; and, for member of inferred [19] $\mathrm{W}_{2}$ structural ensemble with radius-of-gyration closest to that determined by diffusion ordered NMR spectroscopy for $\mathrm{W}_{2} ;{ }^{2}$ Residues having $\left[{ }^{1} \mathrm{H}\right]-{ }^{15} \mathrm{~N}$ NOE $>0.65$ used in ROTDIF [54] fit; ${ }^{3} \mathrm{df}$ : degrees of freedom (equivalent to number of $\mathrm{N}-\mathrm{H}$ bonds).

Ensemble-averaged values of $\tau_{\mathrm{c}}$ based upon anisotropic diffusion tensors demonstrated only modest increases from $7.9 \mathrm{~ns}$ for $\mathrm{W}_{1}$ to $9.0 \mathrm{~ns}$ for $\mathrm{W}_{2-1}$ to $9.6 \mathrm{~ns}$ for $\mathrm{W}_{2-2}$. To place this behaviour in context, a variety of rotational correlation time $\left(\tau_{c}\right)$ estimations were compared (Table 2). Using Stokes' law (Equation (5)), crude values of $\tau_{\mathrm{c}}$ were estimated both according to an assumption of spherical shape (Equation (6)) and according to our previously reported hydrodynamic radii determined by diffusion ordered NMR spectroscopy (DOSY) and verified by dynamic light scattering [19]. Our NMR-derived $W_{1}$ structural ensemble and the inferred $W_{2}$ structural ensemble were also used for detailed hydrodynamics calculations in HYDROPRO [55] to estimate $\tau_{\mathrm{c}}$. To test the effect of a more compact globular tumbling unit, $\tau_{\mathrm{c}}$ values were also determined for the $\mathrm{W}_{1}$ globular core (i.e., excluding the $\mathrm{N}$ - and C-terminal tails) with and without the inclusion of the more dynamic (Figure 4) and less stable helix $5[19,22]$. It should also be noted that the viscosities employed for the Stokes' law and HYDROPRO hydrodynamics calculations (Table 2) were experimentally determined, rather than estimated. This determination was carried out through DOSY experiments with use of an internal dioxane standard [56]. Estimated $\tau_{c}$ values for $W_{1}$ were most consistent with the experimentally-observed behaviour for the most compact estimates of its conformation. $W_{2}$, conversely, was estimated regardless of the hydrodynamic model employed to tumble much more slowly than was experimentally observed for each globular unit in the concatemer.

The ratio of $T_{1}$ to $T_{2}$ can also be related to $\tau_{\mathrm{c}}$ for the tumbling of a macromolecule in solution under the qualification that the ${ }^{1} \mathrm{H}_{-}-{ }^{15} \mathrm{~N}$ spin pair in question does not experience significant rapid internal motion [27]. Extending this treatment, measured backbone relaxation time constants may be modified (giving $T_{1}{ }^{\prime}$ and $T_{2}{ }^{\prime}$, Equations (1) and (2), respectively) to remove high frequency spectral density contributions [17]. The ratio of these modified relaxation time constants, $\varrho$ (Equation (3)), is relatively insensitive to localized variations in dipolar coupling and ${ }^{15} \mathrm{~N}$ chemical shift anisotropy and, for a protein core, primarily dependent on overall tumbling. Direct comparison of the estimated $\tau_{\mathrm{c}}$ obtained from average values of $T_{1} / T_{2}$ or $T_{1}{ }^{\prime} / T_{2}{ }^{\prime}$ on the basis of the ${ }^{15} \mathrm{~N}$ relaxation analysis of Kay et al. [27] neglecting high-frequency terms (Equation (7)) demonstrates excellent agreement with the far more rigorous ROTDIF calculation.

At a more global level, discrete differences in $1 / \varrho$ are apparent between the globular core vs. tail and linker regions of $W_{1}, W_{2-1}$, and $W_{2-2}$ (Figure 5), with the core of $W_{1}$ being significantly decreased in $1 / \varrho(p$-value $<0.0001)$ relative to $W_{2-1}$ or $W_{2-2}$ and mirroring of this behaviour by helix 5 ( $p$-value $<0.01$ ) (Figure $5 \mathrm{~B}$ ). Following the same trend as $J(0)$ (Figure 4$), \mathrm{W}_{1}$ has a statistically significantly lower mean ( $p$-value $<0.0001) 1 / \varrho$ in the core compared to $W_{2-1} ; W_{2-1}$ is again significantly lower than $W_{2-2}(p$-value $<0.0001)$, reflecting differences in rotational diffusion between $W_{1}$ and each of the $\mathrm{W}$ units in $\mathrm{W}_{2}$ (Figure 5; Table 1). Additionally, regardless of being in a tail or linker, the corresponding residues in a given $W$ unit in $W_{2}$ (i.e., residues 1-11 relative to 201-211 and 150-200 relative to $350-400)$ demonstrate very similar mean $1 / \varrho$ values. The variance accompanying $1 / \varrho$ is, however, too great to draw significance. 
Table 2. Rotational correlation time $\left(\tau_{\mathrm{c}}\right)$ for indicated protein according to given method.

\begin{tabular}{|c|c|c|c|c|c|c|c|}
\hline \multirow{2}{*}{ Protein } & \multirow{2}{*}{$\eta(\mathrm{cP})^{1}$} & \multicolumn{6}{|c|}{$\tau_{\mathrm{c}}(\mathrm{ns})$} \\
\hline & & Stokes (Ideal) $^{2}$ & Stokes (DOSY) ${ }^{3}$ & Structure ${ }^{4}$ & $T_{1} / T_{2}{ }^{5}$ & $T_{1}^{\prime} / T_{2}^{\prime 5}$ & ROTDIF $^{6}$ \\
\hline $\mathrm{W}_{1}$ & 1.040 & $7.8-9.9$ & 10.6 & $\begin{array}{c}14.1 \pm 0.3^{7} \\
9.4 \pm 0.2^{8} \\
8.4 \pm 0.1^{9}\end{array}$ & 7.9 & 8.0 & $7.9 \pm 0.01$ \\
\hline $\mathrm{W}_{2-1}$ & 1.056 & - & - & - & 9.0 & 9.1 & $9.0 \pm 0.01$ \\
\hline $\mathrm{W}_{2-2}^{2-1}$ & 1.056 & - & - & - & 9.5 & 9.6 & $9.6 \pm 0.01$ \\
\hline $\mathrm{W}_{2}$ & 1.056 & $14.7-17.8$ & 19.7 & $31.8 \pm 0.7$ & 9.3 & 9.4 & $9.3 \pm 0.03$ \\
\hline
\end{tabular}

${ }^{1}$ Viscosities determined using dioxane internal standard by DOSY (Equation (4)); ${ }^{2}$ Calculated using Stokes' law (Equation (5)) for a $100 \%{ }^{15} \mathrm{~N} /{ }^{13} \mathrm{C}$-enriched protein mass using a hydration shell of either $1.6 \AA$ (lower estimate) or $3.2 \AA$ (upper estimate), assuming spherical shape (Equation (6)); ${ }^{3}$ Calculated using Stokes' law (Equation (5)) based upon hydrodynamic radii determined by DOSY [19]; ${ }^{4}$ Average \pm average deviation of HYDROPRO [55] predicted $\tau_{c}$ over 20-member ensembles of structures of $W_{1}$ or $W_{2}$ [19], or over globular core of $\mathrm{W}_{1} ;{ }^{5}$ Determined based upon indicated relaxation time constant ratio using Equation (7); ${ }^{6}$ Average \pm average deviation over all 20 structural ensemble members determined through axially-symmetric diffusion tensor ROTDIF in identical manner to Table $1 ;{ }^{7}$ Entire $W_{1}$ structure; ${ }^{8}$ Globular core (residues $12-149$ ); and, ${ }^{9}$ Globular core excluding helix 5 (residues 12-128).
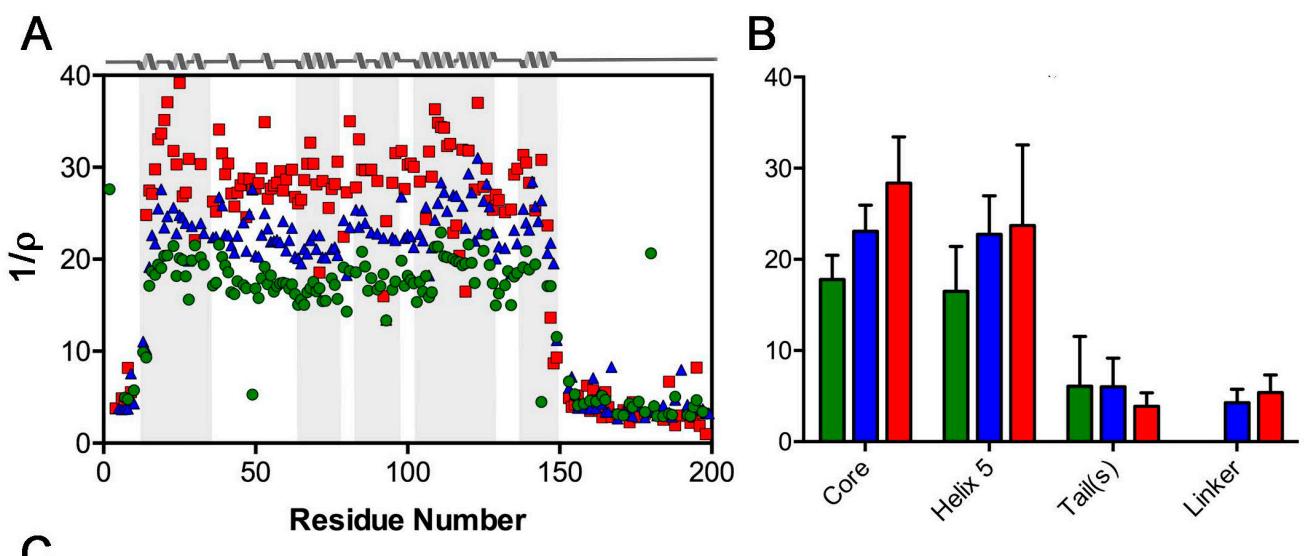

C

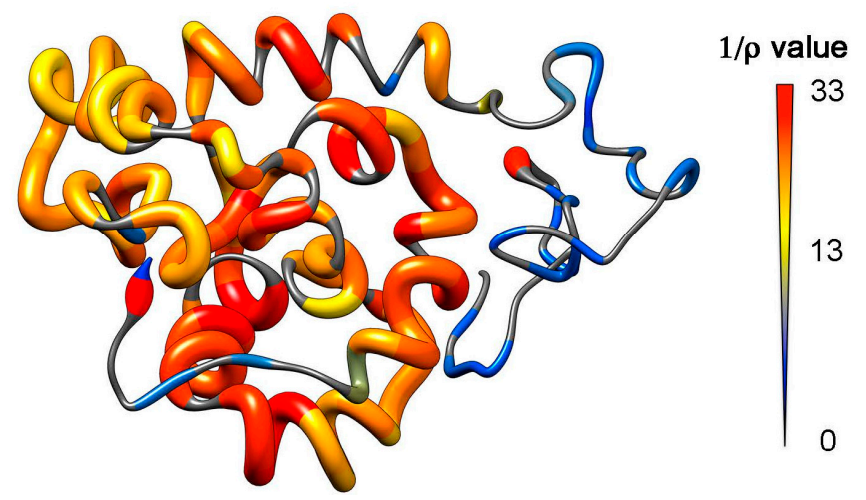

Figure 5. Inverse of $\varrho$ ratio of $T_{1}{ }^{\prime}$ to $T_{2}{ }^{\prime}$ (relaxation times modified to remove high-frequency components of spectral density) as defined by Fushman et al. [17]. (A) Plotted as a function of residue (green circles: $\mathrm{W}_{1}$; blue triangles: $\mathrm{W}_{2-1}$, red squares: $\mathrm{W}_{2-2}$ ) with secondary structuring of the W unit depicted on the basis of PDB entry 2MU3 [19] using grey shading to delineate each helical segment (B) bar graphs for mean (green: $\mathrm{W}_{1}$; blue: $\mathrm{W}_{2-1}$, red: $\mathrm{W}_{2-2}$; error bars: standard deviation) over key $\mathrm{W}$ unit regions. These were specifically defined as the core (residues $12-149\left(\mathrm{~W}_{1}, \mathrm{~W}_{2-1}\right)$ and 212-349 $\left(W_{2-2}\right)$ ), linker (residues 150-211 from $W_{2-1}$ and $\left.W_{2-2}\right)$, tails $\left(W_{1}\right.$ : residues 1-11 and 150-199; $\mathrm{W}_{2}$ : residues 1-11 and 350-400), and helix 5 (residues 135-149 $\left(\mathrm{W}_{1}, \mathrm{~W}_{2-1}\right)$ and 335-349 $\left(\mathrm{W}_{2-2}\right)$ ); and (C) plotted for $W_{1}$ on the lowest-energy NMR ensemble member of PDB entry 2MU3 [19], with both backbone thickness and colour varied as a function of $1 / \varrho$, as indicated. 


\section{Discussion}

AcSp1 from A. trifasciata is a modular protein composed primarily of a repetitive domain of concatenated 200 amino acid $\mathrm{W}$ units [4]. We recently demonstrated that the $\mathrm{W}$ unit is composed of a well-folded globular domain of 138 residues connected to adjacent globular domains by intrinsically-disordered linkers $\sim 62$ residues in length [19]. The functional necessity of this folded domain is further implied from the fact that it appears to be highly conserved (albeit considering a limited number of sequenced species), while the linker may vary both in length and sequence [57].

The modularity of AcSp1 was established through direct backbone chemical shift comparison between the monomeric $\left(\mathrm{W}_{1}\right)$ and concatemeric $\left(\mathrm{W}_{2}\right)$ states of AcSp1. Specifically, the chemical shifts of $W_{2}$ are remarkably similar to $W_{1}$ with exception of those in the linker immediately proximal to the covalent $\mathrm{W}$ unit linkage [19]. Beyond conservation of chemical shifts, heteronuclear $\left[{ }^{1} \mathrm{H}\right]-{ }^{15} \mathrm{~N}$ NOE data recorded at $16.4 \mathrm{~T}$ (Figure 1) also uphold the conformational independence of $\mathrm{W}$ units, given that $W_{1}$ and each of the $W$ units in $W_{2}$ exhibit very similar NOE enhancement factor patterns as a function of position within the W unit [19]. In each case, higher NOE enhancement factors are exhibited in the folded domain (residues 12-149, numbering relative to each $\mathrm{W}$ unit) and lower or negative enhancements in the disordered terminal or linker regions (residues 1-11,150-200) (Figure 1). The effect of concatemeric linking of $W$ units is observed in the vicinity of the covalent linkage of the $\mathrm{W}$ units (residues 190 to 210 of $\mathrm{W}_{2}$ ) through a less negative NOE enhancement relative to the free $\mathrm{N}$ - and C-terminal tails of $\mathrm{W}_{1}$ and of $\mathrm{W}_{2-1}$ and $\mathrm{W}_{2-2}$, respectively.

Our previous studies showed clear modularity in the $\mathrm{W}$ unit both in terms of structuring of the globular domain and the intrinsic disorder of the linker. The ${ }^{15} \mathrm{~N}$ spin relaxation measurements and reduced spectral density mapping detailed herein demonstrate that this modularity clearly extends beyond structuring and into the dynamic behaviour along the polypeptide backbone. Segmental isotope-labelling mediated by split intein trans-splicing allowed us to track this behaviour unambiguously along the length of $\mathrm{W}_{2}$. It should be noted that the relaxation analysis methods employed herein are limited to probing motions in the ps-ns regime [26], but that the trans-splicing methodology, itself, can be directly applied to other NMR-based methods allowing characterization of longer time-scale motions.

Direct comparison of the $\mathrm{N}$ - and C-terminal $\mathrm{W}$ units in the concatemer was, thus, possible alongside a comparison of $\mathrm{W}_{1}$ to $\mathrm{W}_{2} \cdot T_{1}, T_{2},\left[{ }^{1} \mathrm{H}\right]-{ }^{15} \mathrm{~N} \mathrm{NOE}$, and $1 / \varrho$, in each case, explicitly delineate the globular vs. tail or linker domains (Figures 1, 2 and 5). For the most part, the globular domain exhibits uniform spin relaxation behaviour, with slight localized decreases in the $\left[{ }^{1} \mathrm{H}\right]-{ }^{15} \mathrm{~N}$ NOE delineating the secondary structure elements centred at residue 35-37 (between helix 1 and the converged, predominantly helical region over residues 40-60), residue 61 (between residues 40-60 and helix 2), residues 79-80 (between helices 2 and 3), residues 91-93 (near the helix 3 C-terminus), and residues 128-132 (between helices 4 and 5).

Given the existence of discrete disordered and globular domains in the W unit, we employed the ${ }^{15} \mathrm{~N}$ reduced spectral density mapping approach [30] to analyze backbone dynamics, rather than the model-free [28] or extended model-free [29] formalism. This approach alleviates the requirement for defining specific motional modes and their independence or lack thereof, with demonstrated suitability for proteins of mixed ordered and disordered segments [52]. The resulting values of the spectral density function at three frequencies, $J(0), J\left(\omega_{\mathrm{N}}\right)$, and $J\left(0.87 \omega_{\mathrm{H}}\right)$, derived from relaxation parameters $T_{1}, T_{2}$, and $\left[{ }^{1} \mathrm{H}\right]-{ }^{15} \mathrm{~N}$ NOE provide complimentary information along the peptide backbone (Figures 3 and 4) and unequivocally support our original model of $W_{2}$, based on $W_{1}$ restraints [19], with the tail/linker regions and the globular domain being noticeably segregated.

$J\left(\omega_{\mathrm{N}}\right)$ is much less sensitive to internal motions at the ps-ns time scale in comparison to $J(0)$ and $J\left(0.87 \omega_{\mathrm{H}}\right)$ and displays very little variability between the folded domain and the linker. The residues in the folded domain have large $J(0)$ and small $J\left(0.87 \omega_{\mathrm{H}}\right)$, while the linker and tail regions display the opposite trend (Figures 3 and 4). This is consistent with a situation where the linker and tails experience motion over a wider range of frequencies relative to the globular domain, as would be 
expected for an intrinsically disordered domain. Noticeably, the mean $J(0)$ and $J\left(\omega_{N}\right)$ values over the globular domain differ significantly between $\mathrm{W}_{1}, \mathrm{~W}_{2-1}$, and $\mathrm{W}_{2-2}$, increasing or decreasing, respectively, from $W_{1}$ to $W_{2-1}$ to $W_{2-2}$. This behaviour is consistent with an increase in tumbling rates from $W_{1}$ to $\mathrm{W}_{2-1}$ to $\mathrm{W}_{2-2}$.

Based upon both heteronuclear NMR [19] and ${ }^{19}$ F-NMR [22], helix 5 (residues 135-149) and the portion of the globular domain in contact with it (falling in proximity to residue 36) are less stable than the remainder of the protein. Chaotropic denaturation or treatment with the detergent dodecylphopshocholine lead to helix 5 destabilization and a concomitant structural rearrangement in the globular core of the W unit $[19,22]$. Notably, therefore, the spectral density in helix 5 deviates from the remainder of the globular domain. Direct comparison to the proximal helix 4 shows elevated spectral density at $J\left(0.87 \omega_{\mathrm{H}}\right) . J(0)$ is also qualitatively lower for helix 5 than for the remainder of the globular core (helix 1-4) (Figure 3). This behaviour, as a whole, is consistent with a greater sampling of high-frequency motion in this region of the $\mathrm{W}$ unit regardless of whether it is in an isolated $\mathrm{W}$ unit or a concatemeric construct.

Helix 5 falls immediately N-terminal to the intrinsically disordered linker. Our working hypothesis is that decompaction of the $\mathrm{W}$ unit occurs through loss of interaction of helix 5 with the core [22] followed by denaturation [19]. This would, in turn, greatly favour protein-protein entangling and interaction, inducing subsequent $\beta$-sheet formation during fibrillogenesis. Backbone-level dynamics are consistent with the distinct behaviour of helix 5 relative to the remainder of the globular domain and unambiguously demonstrate a propensity for increased high frequency motion.

Before considering rotational tumbling behaviour in more detail, it should be noted that the viscosities measured for the $\mathrm{W}_{1}$ and $\mathrm{W}_{2}$ samples in NMR buffer (Table 2) are significantly higher than the $\sim 0.82 \mathrm{cP}$ that is derived on the basis of a linear combination of the expected [58] $\mathrm{H}_{2} \mathrm{O}$ and $\mathrm{D}_{2} \mathrm{O}$ viscosities at $30^{\circ} \mathrm{C}$. The source of this elevated viscosity is not fully clear. Given that $\mathrm{W}_{1}$ will, for example, spontaneously form nanoparticle (or micellar) structures in aqueous solution [59], supramolecular assembly was certainly a distinct possibility. Neither spin relaxation behaviour (Table 2) nor translational diffusion observed by DOSY [19] are consistent with long-lived entanglement of the proteins or of stable oligomer formation. Were entanglement, oligomerization, or nanoparticle/micelle formation happening in the bulk of the sample, substantially slower tumbling and diffusion than observed would be expected. The fact that the vast majority of protein in solution is still fully observable on the basis of both spin relaxation behaviour and signal intensity by heteronuclear ([19] and herein) and ${ }^{19} \mathrm{~F}$ [22] NMR implies that if intermolecular entangling and/or supramolecular assembly are occurring and increasing solution viscosity that this only involves a small fraction of the total protein.

Tumbling of $W_{1}$, reflected in the observed $\tau_{\mathrm{c}}$ of $7.9 \mathrm{~ns}$, is more rapid than would be anticipated strictly on the basis of the $\mathrm{W}_{1}$ hydrodynamic radius previously determined though DOSY [19] or through hydrodynamics calculations using the $W_{1}$ structural ensemble (Table 2). $W_{1}$, instead, exhibits tumbling consistent with a compact spherical particle of the same molecular weight with a half-shell of water. The overestimates in $\tau_{c}$ on the basis of overall $W_{1}$ shape and dimensions are not surprising, given that the presence of intrinsically disordered domains in a protein leads to a general overestimation of $\tau_{c}$ by methods (such as HYDROPRO) that employ an assumption of rigid behaviour [60,61]. Truncation of the $W_{1}$ structure either to the globular core or to the core without helix 5 lead to improved agreement between the inferred and observed $\tau_{\mathrm{c}}$ values, with the helix $1-4$ globular core leading to a predicted $\tau_{\mathrm{c}}$ of $\sim 8.4 \mathrm{~ns}$. Rotational diffusion is, therefore, most consistent with a compact globular core where helix 5 is not always attached. Translational diffusion, conversely, agrees well with the overall shape of $\mathrm{W}_{1}[19]$.

Modest increases in $\tau_{\mathrm{c}}$, to $9.0 \mathrm{~ns}$ for $\mathrm{W}_{2-1}$ and $9.6 \mathrm{~ns}$ for $\mathrm{W}_{2-2}$, are observed relative to $7.9 \mathrm{~ns}$ for $\mathrm{W}_{1}$. These values are $\sim 2 / 3$ of those predicted for a compact sphere and $\sim 1 / 2$ those predicted on the basis of the DOSY-determined $W_{2}$ hydrodynamic radius and $<1 / 3$ that predicted by HYDROPRO on the basis of the $W_{2}$ structural ensemble. This behaviour is also directly reflected in the magnitude of the observed increases in $1 / \varrho$ from $W_{1}$ to $W_{2-1}$ to $W_{2-2}$ (Figure 5). Namely, $W_{2}$ does not exhibit 
anywhere near the expected [17] doubling of $1 / \varrho$ relative to $W_{1}$ that would be observed if the two $\mathrm{W}$ units in $\mathrm{W}_{2}$ were rigidly tumbling together as a species of double the molecular weight. Following studies using ensemble methods to accurately predict rotational diffusion for molecules containing intrinsically-disordered linkers [61,62], this is instead consistent with mostly decoupled tumbling of each globular domain. The increased $\tau_{c}$ of $W_{2-2}$ relative to $W_{2-1}$ is consistent with greater hydrodynamic friction experienced from the asymmetric nature of the tails, with an $\sim 11$ residue disordered $\mathrm{N}$-terminal tail for $\mathrm{W}_{2-1}$ vs. an $\sim 50$ residue disordered C-terminal tail for $\mathrm{W}_{2-2}$.

\section{Materials and Methods}

\subsection{Sample Preparation}

Protein samples were prepared by recombinantly expressing $\mathrm{W}_{1}$ and $\mathrm{W}_{2}$ in Escherichia coli BL21(DE3), following previously-described protocols $[19,63]$. It should be noted that $\mathrm{W}_{1}$ consists of residues 1-199 of the AcSp1 repeat unit from A. trifasciata while $\mathrm{W}_{2-1}$ and $\mathrm{W}_{2-2}$ each comprise the full 200 amino acid repeat unit concatenated to form a 400 residue protein. An N-terminal Met is also present in $W_{2}$ from the initiation codon; for simplicity of comparison between $W_{1}$ and each unit in $W_{2}$, the Met is not included in residue numbering. Uniformly ${ }^{15} \mathrm{~N}$-enriched $\mathrm{W}_{1}(\sim 0.2 \mathrm{mM})$, and selectively ${ }^{15} \mathrm{~N}$-enriched $\mathrm{W}_{2-1}$ and $\mathrm{W}_{2-2}(\sim 0.2 \mathrm{mM}) \mathrm{NMR}$ samples were prepared in sodium acetate buffer $(20 \mathrm{mM}$ $d_{3}$-acetate (Sigma-Aldrich Canada, Oakville, ON, Canada) in $\mathrm{H}_{2} \mathrm{O}: \mathrm{D}_{2} \mathrm{O}$ (Sigma-Aldrich Canada) at 90\%:10\% (v/v), $1 \mathrm{mM} \mathrm{NaN}_{3}$ (Sigma-Aldrich Canada), $1 \mathrm{mM}$ 2,2-dimethyl-2-silapentane-5-sulfonic acid (DSS) (Wilmad, Buena, NJ, USA); pH 5).

\subsection{Spin-Relaxation NMR Experiments}

NMR spin relaxation experiments were carried out at $30^{\circ} \mathrm{C}$ on an Avance III NMR spectrometer operating at $16.4 \mathrm{~T}$ (Bruker Canada, Milton, ON, Canada) and equipped with a triple-resonance $5 \mathrm{~mm}$ indirect detect TCI cryoprobe. Two-dimensional phase-sensitive ${ }^{1} \mathrm{H}_{-}{ }^{15} \mathrm{~N}$ HSQC experiments were used to measure longitudinal relaxation times ( $T_{1}$; hsqctletf3gpsi pulse program, Bruker library) and transverse relaxation times ( $T_{2}$; hsqct2etf3gpsi pulse program, Bruker library). All experiments were performed using 16 scans, $1.5 \mathrm{~s}$ recycle delay for $\mathrm{W}_{1}$ and $1.75 \mathrm{~s}$ for $\mathrm{W}_{2-1}$ and $\mathrm{W}_{2-2}$, spectral widths of 23 and $16 \mathrm{ppm}$ with offsets of $115.5 \mathrm{ppm}$ and at the water frequency $(4.705 \mathrm{ppm})$, respectively, for ${ }^{15} \mathrm{~N}$ and ${ }^{1} \mathrm{H}$. $\mathrm{W}_{1}$ spectra contained $192 \times 2048$ complex points and $\mathrm{W}_{2-1}$ and $\mathrm{W}_{2-2}$ contained $128 \times 2048$ complex points for the ${ }^{15} \mathrm{~N}$ and ${ }^{1} \mathrm{H}$, respectively. The $T_{1}$ data were collected using relaxation delays of 50,100, 250, 500, 750, 1000, 1300, and $1700 \mathrm{~ms}$ and the $T_{2}$ data were collected using 17, 34, 51, 85, $119,152,187$, and $238 \mathrm{~ms}$ relaxation delays, with a Carr-Purcell-Meiboom-Gill pulse train applied as appropriate for a given relaxation delay during the recycle delay to compensate for heating effects. $\left[{ }^{1} \mathrm{H}\right]-{ }^{15} \mathrm{~N}$ steady-state heteronuclear nuclear Overhauser effects $\left(\left[{ }^{1} \mathrm{H}\right]-{ }^{15} \mathrm{~N}\right.$ NOE; hsqcnoef3gpsi pulse program, Bruker library) for the ${ }^{15} \mathrm{~N}$ nuclei were measured in an interleaved manner as described previously [19]. Briefly, the $\left[{ }^{1} \mathrm{H}\right]-{ }^{15} \mathrm{~N}$ NOE measurements were performed using a total of $356 \times 4096$ complex points with 32 transients for $\mathrm{W}_{1}$ and $256 \times 4096$ complex points and 32 transients for both $\mathrm{W}_{2}$ domains.

\subsection{Determination of Spin Relaxation Parameters and Reduced Spectral Density mapping}

Backbone ${ }^{15} \mathrm{~N} T_{1}, T_{2}$, and $\left[{ }^{1} \mathrm{H}\right]-{ }^{15} \mathrm{~N}$ NOE as a function of ${ }^{1} \mathrm{H}_{-}{ }^{15} \mathrm{~N}$ cross-peak position were determined and correlated to our previously assigned chemical shifts (deposited in the Biological Magnetic Resonance Data Bank for $W_{1}$ (BMRB entry 17899) and $W_{2}$ (BMRB entry 25197) $[19,63]$ ). The ${ }^{15} \mathrm{~N}_{1}$ and $T_{2}$ values with associated errors were determined using the Mathematica version 8.0.4 (Wolfram, Champaign, IL, USA) notebook Relaxation Decay, freely available from Leo Spyracopoulos [51]. $R_{1}\left(R_{1}\left(\mathrm{~s}^{-1}\right)=1 / T_{1}\right)$ and $R_{2}\left(R_{2}\left(\mathrm{~s}^{-1}\right)=1 / T_{2}\right)$ relaxation rates were determined from nonlinear least-square fits to a two-parameter monoexponential decay. Errors were estimated based on the average spectral noise. The $\left[{ }^{1} \mathrm{H}\right]-{ }^{15} \mathrm{~N}$ heteronuclear NOE was measured as the ratio of 
the saturated spectrum to the reference spectrum as $I_{\text {sat }} / I_{\text {ref }}$ where $I_{\text {sat }}$ and $I_{\text {ref }}$ are the intensities of the peaks in the ${ }^{1} \mathrm{H}_{-}{ }^{15} \mathrm{~N}$ HSQC spectra, with and without proton saturation during the recycle delay, respectively. Non-linear fits were used to minimize the statistical value of $\chi^{2}$. The $\chi^{2}$ goodness-of-fit test per residue was used and compared to the exact critical $\chi^{2}$ determined from 100 Monte Carlo simulations (9.146) for a single residue at a $95 \%$ confidence interval:

$$
1 / T_{1}{ }^{\prime}=R_{1}{ }^{\prime}=R_{1}[1-1.249|\gamma \mathrm{N} / \gamma \mathrm{H}|(1-\mathrm{NOE})]
$$

and:

$$
1 / T_{2}^{\prime}=R_{2}^{\prime}=R_{2}-1.079\left|\gamma_{\mathrm{N}} / \gamma_{\mathrm{H}}\right| R_{1}(1-N O E)
$$

where $\gamma_{\mathrm{N}}$ and $\gamma_{\mathrm{H}}$ are the gyromagnetic ratios of ${ }^{15} \mathrm{~N}$ and ${ }^{1} \mathrm{H}$, respectively. The ratio of these modified rates, was calculated as:

$$
\varrho=\left[\left(2 R_{2}^{\prime} / R_{1}^{\prime}\right)-1\right]^{-1}
$$

Finally, per-residue values of $J(0), J\left(\omega_{\mathrm{N}}\right)$, and $J\left(0.87 \omega_{\mathrm{H}}\right)$ were determined through ${ }^{15} \mathrm{~N}$ reduced spectral density mapping [30] using the Spectral Density Mathematica notebook [51].

\subsection{Viscosity Determination}

The viscosity ( $\eta$ ) of each NMR sample was calculated using a dioxane internal standard [56]. DOSY experiments acquired and processed as detailed previously for $W_{1}$ and $W_{2}$ [19] were analyzed to directly determine the translational diffusion coefficient $\left(D_{\mathrm{C}}\right)$ for dioxane in a given $\mathrm{W}$ sample. Coupling each measured $\mathrm{D}_{\mathrm{C}}$ with the known hydrodynamic diameter $\left(d_{\mathrm{H}}\right)$ of dioxane $(0.424 \mathrm{~nm}[56])$, $\eta$ may be determined through the Stokes-Einstein equation [64]:

$$
D_{\mathrm{C}}=\left(\mathrm{k}_{\mathrm{B}} \mathrm{T}\right) /\left(3 \pi \eta d_{\mathrm{H}}\right)
$$

where $\mathrm{k}_{\mathrm{B}}$ is the Boltzmann constant and $\mathrm{T}$ the absolute temperature (303 K).

\subsection{Analysis of Rotational Diffusion}

To analyze rotational diffusion behaviour with respect the ${ }^{15} \mathrm{~N}$ spin relaxation data, isotropic, axially symmetric, and anisotropic diffusion tensors models were applied to $W_{1}, W_{2-1}$, and $W_{2-2}$ using ROTDIF 3.1 [54]. Only residues with $\left[{ }^{1} \mathrm{H}\right]-{ }^{15} \mathrm{~N}$ NOE $>0.65$ and not likely to be involved in conformational exchange were used for the analysis. For $\mathrm{W}_{1}, \mathrm{~W}_{2-1}$, and $\mathrm{W}_{2-2}$, the 20-member $\mathrm{W}_{1}$ structural ensemble (PDB ID 2MU3) was iteratively analyzed through ROTDIF using robust least-square fitting to obtain global information with coordinates from the lowest energy member to model the diffusion tensor frame $\left(D_{||}\right.$and $D_{\perp}$ tensor axes for an axially symmetric system, or $D_{x x}$, $D_{y y}$, and $D_{z z}$ tensor axes for a fully anisotropic system) and Euler angles $(\alpha, \beta$, and /or $\gamma)$. In addition, the $W_{2}$ ensemble member with the calculated $R_{g}$ closest to the experimental $R_{g}$ was deemed the representative model for the reference frame of the diffusion tensor for $W_{2}$ (merged $W_{2-1}$ and $W_{2-2}$ relaxation data). The robust least-squares optimization method was employed during fitting and full statistical analysis was employed to determine the most statistically upheld diffusion tensor model for a given ensemble member.

\subsection{Estimations of Rotational Correlation Time}

The rotational correlation time $\left(\tau_{\mathrm{c}}\right)$, assuming a hydrated sphere, may be estimated through Stokes' law [64]:

$$
\tau_{\mathrm{c}}=\left(4 \pi \eta r_{\mathrm{H}}^{3}\right) /\left(3 \mathrm{k}_{\mathrm{B}} \mathrm{T}\right)
$$

where $r_{\mathrm{H}}$ is the radius of hydration. For a hydrated protein, $r_{\mathrm{H}}$ may be roughly estimated on the basis of the specific volume $\left(v=0.73 \mathrm{~cm}^{3} / \mathrm{g}\right)$ as [65]: 


$$
r_{\mathrm{H}}=\left[3 v M_{\mathrm{r}} /\left(4 \pi N_{\mathrm{A}}\right)\right]^{1 / 3}+r_{\mathrm{w}}
$$

where $M_{\mathrm{r}}$ is the molecular weight, $N_{\mathrm{A}}$ is Avogadro's number, and $r_{\mathrm{W}}$ is radius of the hydration layer surrounding the protein (1.6-3.2 $\AA$ for $\frac{1}{2}-1$ hydration shell [66]).

For direct comparison, the average ratios of $T_{1} / T_{2}\left(\right.$ or $\left.T_{1}{ }^{\prime} / T_{2}{ }^{\prime}\right)$ for all residues with an NOE $>0.65$ in a given protein were employed to estimate $\tau_{c}$. Through neglecting of the high-frequency terms of the spectral density, the analysis of Kay et al. [27] may be simplified to:

$$
\tau_{\mathrm{c}}=\left[1 /\left(4 \pi v_{\mathrm{N}}\right)\right]\left(6 T_{1} / T_{2}-7\right)^{1 / 2}
$$

where $v_{\mathrm{N}}$ is the resonance frequency of ${ }^{15} \mathrm{~N}$ (in $\mathrm{Hz}$ ).

HYDROPRO [55] was also used to estimate ensemble-averaged $\tau_{c}$ values based upon the NMR-derived structural ensemble for $\mathrm{W}_{1}$ (PDB entry 2MU3) and the $\mathrm{W}_{2}$ ensemble inferred on the basis of concatenated NMR-derived restraints for $W_{1}$ [19]. The resulting output was parsed for $\tau_{c}$ (harmonic mean (correlation) time) as calculated on the basis of the combined input of temperature, solvent viscosity, molecular weight, solute partial specific volume, solution density, and PDB structural coordinates. For comparison, calculations were carried out for $\mathrm{W}_{1}$ structural ensembles truncated using an in-house Tcl/Tk script to the globular core (residues 12-149) or the globular core excluding both the turn between helices 4 and 5 and helix 5 (residues 12-128).

\subsection{Statistical Tests}

Statistical analyses were performed between units and protein regions as described above to evaluate significance between means through ordinary one-way ANOVA test when comparing 3 or more means or unpaired two tailed $t$-test with Welch's correction for unequal variances when comparing two means within the Prism 6 or InStat software packages (both from GraphPad Software Inc., La Jolla, CA, USA). All distributions were assumed to be Gaussian. Unless otherwise noted, significance was determined at an $\alpha$ of 0.05 .

\section{Conclusions}

The core repetitive domain of AcSp1 is composed of concatenated 200 amino acid units, identical in sequence and very similar in tertiary structuring and internal motions. Through split intein-mediated trans-splicing, individual repeat units were selectively isotope-enriched and investigated in the context of the $\mathrm{W}_{2}$ protein capable of fibrillogenesis. Intein-mediated segmental-labelling is also highly promising for future studies of other modular proteins, whereby spectral complexity can be reduced without compromising the functional state of the protein. Backbone-level dynamics very clearly demonstrate the beads-on-a-string conformation of the AcSp1 repetitive domain, with structured globular domains linked by lengthy intrinsically-disordered segments forming a relatively viscous solubilized state. Although our previous translational diffusion studies imply that the linker is not highly extended, with $W_{2}$ and $W_{3}$ exhibiting relatively compact conformations, the ${ }^{15} \mathrm{~N}$ spin relaxation behaviour detailed herein demonstrate that each globular domain in $\mathrm{W}_{2}$ tumbles nearly independently of its neighbour. Regardless of the construct examined, helix 5 also exhibited elevated high-frequency dynamics relative to the remainder of the globular core. Rotational diffusion behaviour of $W_{1}$ is also most consistent with a $\mathrm{W}$ unit globular core where helix 5 is not stably attached. Unambiguous measurement of backbone dynamics, therefore, improves our understanding of both AcSp1 repetitive domain modularity and allow direct demonstration of variations in localized stability that were implied by titration with chaotropes and detergent.

Acknowledgments: Thanks to Bruce Stewart for expert technical assistance; Leo Spyracopoulos for helpful discussions; and, Ian Burton, Nadine Merkley, and Ray Syvitski for 16.4 T NMR spectrometer support at the National Research Council Biological Magnetic Resonance Facility (NRC-BMRF, Halifax, NS, Canada) accessed through Dalhousie's Nuclear Magnetic Resonance Resource (NMR3). This work was supported by Discovery Grants from the Natural Sciences and Engineering Research Council of Canada (NSERC; RGPIN/342034-2012 
to Jan K. Rainey and RGPIN/41823-2015 to Xiang-Qin Liu); key infrastructure was provided through NSERC Research Tools and Instruments Grants and a Leaders Opportunity Fund award from the Canadian Foundation for Innovation (to Jan K. Rainey); and, a Dalhousie Medical Research Foundation Capital Equipment Grant (to Jan K. Rainey and Xiang-Qin Liu). The TCI probe for the 16.4 T NMR spectrometer at the NRC-BMRF were provided by Dalhousie University through an Atlantic Canada Opportunities Agency Grant. Jan K. Rainey is supported by a Canadian Institutes for Health Research New Investigator Award and Marie-Laurence Tremblay was supported by an NSERC Doctoral Postgraduate Scholarship.

Author Contributions: Xiang-Qin Liu and Jan K. Rainey conceived the research; Lingling Xu and Marie-Laurence Tremblay prepared protein samples; Marie-Laurence Tremblay, Muzaddid Sarker and Jan K. Rainey acquired experimental data; Marie-Laurence Tremblay, Lingling Xu, Muzaddid Sarker, Xiang-Qin Liu and Jan K. Rainey analyzed experimental data; Jan K. Rainey and Marie-Laurence Tremblay wrote the manuscript; all authors edited and commented on the manuscript.

Conflicts of Interest: The authors declare no conflict of interest.

\section{References}

1. Lewis, R.V. Spider silk: Ancient ideas for new biomaterials. Chem. Rev. 2006, 106, 3762-3774. [CrossRef] [PubMed]

2. Yigit, S.; Dinjaski, N.; Kaplan, D.L. Fibrous proteins: At the crossroads of genetic engineering and biotechnological applications. Biotechnol. Bioeng. 2016, 113, 913-929. [CrossRef] [PubMed]

3. Zhou, C.Z.; Confalonieri, F.; Medina, N.; Zivanovic, Y.; Esnault, C.; Yang, T.; Jacquet, M.; Janin, J.; Duguet, M.; Perasso, R.; et al. Fine organization of Bombyx mori fibroin heavy chain gene. Nucleic Acids Res. 2000, 28, 2413-2419. [CrossRef] [PubMed]

4. Hayashi, C.Y.; Blackledge, T.A.; Lewis, R.V. Molecular and mechanical characterization of aciniform silk: Uniformity of iterated sequence modules in a novel member of the spider silk fibroin gene family. Mol. Biol. Evol. 2004, 21, 1950-1959. [CrossRef] [PubMed]

5. Pickford, A.R.; Campbell, I.D. NMR studies of modular protein structures and their interactions. Chem. Rev. 2004, 104, 3557-3566. [CrossRef] [PubMed]

6. Han, J.H.; Batey, S.; Nickson, A.A.; Teichmann, S.A.; Clarke, J. The folding and evolution of multidomain proteins. Nat. Rev. Mol. Cell Biol. 2007, 8, 319-330. [CrossRef] [PubMed]

7. Levitt, M. Nature of the protein universe. Proc. Natl. Acad. Sci. USA 2009, 106, 11079-11084. [CrossRef] [PubMed]

8. Frueh, D.P.; Goodrich, A.C.; Mishra, S.H.; Nichols, S.R. NMR methods for structural studies of large monomeric and multimeric proteins. Curr. Opin. Struct. Biol. 2013, 23, 734-739. [CrossRef] [PubMed]

9. Ravera, E.; Salmon, L.; Fragai, M.; Parigi, G.; Al-Hashimi, H.; Luchinat, C. Insights into domain-domain motions in proteins and RNA from solution NMR. Acc. Chem. Res. 2014, 47, 3118-3126. [CrossRef] [PubMed]

10. Kikhney, A.G.; Svergun, D.I. A practical guide to small angle X-ray scattering (SAXS) of flexible and intrinsically disordered proteins. FEBS Lett. 2015, 589, 2570-2577. [CrossRef] [PubMed]

11. Smith, J.L.; Skiniotis, G.; Sherman, D.H. Architecture of the polyketide synthase module: surprises from electron cryo-microscopy. Curr. Opin. Struct. Biol. 2015, 31, 9-19. [CrossRef] [PubMed]

12. Maciejewski, M.; Barlow, P.N.; Tjandra, N. Decoding the components of dynamics in three-domain proteins. J. Comput. Chem. 2014, 35, 518-525. [CrossRef] [PubMed]

13. Ryabov, Y.E.; Fushman, D. A model of interdomain mobility in a multidomain protein. J. Am. Chem. Soc. 2007, 129, 3315-3327. [CrossRef] [PubMed]

14. Wagner, M.J.; Stacey, M.M.; Liu, B.A.; Pawson, T. Molecular mechanisms of SH2- and PTB-domain-containing proteins in receptor tyrosine kinase signaling. Cold Spring Harb. Perspect. Biol. 2013, 5, a008987. [CrossRef] [PubMed]

15. Horn, A.H.; Sticht, H. Synthetic protein scaffolds based on peptide motifs and cognate adaptor domains for improving metabolic broductivity. Front. Bioeng. Biotechnol. 2015, 3, 191. [CrossRef] [PubMed]

16. Castaneda, C.A.; Spasser, L.; Bavikar, S.N.; Brik, A.; Fushman, D. Segmental isotopic labeling of ubiquitin chains to unravel monomer-specific molecular behavior. Angew. Chem. Int. Ed. 2011, 50, 11210-11214. [CrossRef] [PubMed]

17. Fushman, D.; Varadan, R.; Assfalg, M.; Walker, O. Determining domain orientation in macromolecules by using spin-relaxation and residual dipolar coupling measurements. Prog. Nucl. Magn. Reson. Spectrosc. 2004, 44, 189-214. [CrossRef] 
18. Walsh, J.D.; Meier, K.; Ishima, R.; Gronenborn, A.M. NMR studies on domain diffusion and alignment in modular GB1 repeats. Biophys. J. 2010, 99, 2636-2646. [CrossRef] [PubMed]

19. Tremblay, M.L.; Xu, L.; Lefevre, T.; Sarker, M.; Orrell, K.E.; Leclerc, J.; Meng, Q.; Pezolet, M.; Auger, M.; Liu, X.Q.; et al. Spider wrapping silk fibre architecture arising from its modular soluble protein precursor. Sci. Rep. 2015. [CrossRef] [PubMed]

20. Xu, L.; Rainey, J.K.; Meng, Q.; Liu, X.Q. Recombinant minimalist spider wrapping silk proteins capable of native-like fiber formation. PLOS ONE 2012, 7, e50227. [CrossRef] [PubMed]

21. Lefèvre, T.; Boudreault, S.; Cloutier, C.; Pezolet, M. Diversity of molecular transformations involved in the formation of spider silks. J. Mol. Biol. 2011, 405, 238-253. [CrossRef] [PubMed]

22. Sarker, M.; Orrell, K.E.; Xu, L.; Tremblay, M.L.; Bak, J.J.; Liu, X.Q.; Rainey, J.K. Tracking transitions in spider wrapping silk conformation and dynamics by ${ }^{19} \mathrm{~F}$ nuclear magnetic resonance spectroscopy. Biochemistry 2016, 55, 3048-3059. [CrossRef] [PubMed]

23. Mita, K.; Ichimura, S.; James, T.C. Highly repetitive structure and its organization of the silk fibroin gene. J. Mol. Evol. 1994, 38, 583-592. [CrossRef] [PubMed]

24. Weatherbee-Martin, N.; Xu, L.; Hupe, A.; Kreplak, L.; Fudge, D.S.; Liu, X.Q.; Rainey, J.K. Identification of wet-spinning and post-spin stretching methods amenable to recombinant spider aciniform silk. Biomacromolecules 2016, 17, 2737-2746. [CrossRef] [PubMed]

25. Wang, S.; Ladizhansky, V. Recent advances in magic angle spinning solid state NMR of membrane proteins. Prog. Nucl. Magn. Reson. Spectrosc. 2014, 82, 1-26. [CrossRef] [PubMed]

26. Ortega, G.; Pons, M.; Millet, O. Protein functional dynamics in multiple timescales as studied by NMR spectroscopy. Adv. Protein Chem. Struct. Biol. 2013, 92, 219-251. [PubMed]

27. Kay, L.E.; Torchia, D.A.; Bax, A. Backbone dynamics of proteins as studied by ${ }^{15} \mathrm{~N}$ inverse detected heteronuclear NMR spectroscopy: application to staphylococcal nuclease. Biochemistry 1989, 28, 8972-8979. [CrossRef] [PubMed]

28. Lipari, G.; Szabo, A. Model-free approach to the interpretation of nuclear magnetic resonance relaxation in macromolecules. 1. Theory and range of validity. J. Am. Chem. Soc. 1982, 104, 4546-4559. [CrossRef]

29. Clore, G.M.; Szabo, A.; Bax, A.; Kay, L.E.; Driscoll, P.C.; Gronenborn, A.M. Deviations from the simple 2-parameter model-free approach to the interpretation of N-15 nuclear magnetic relaxation of proteins. J. Am. Chem. Soc. 1990, 112, 4989-4991. [CrossRef]

30. Farrow, N.A.; Zhang, O.; Szabo, A.; Torchia, D.A.; Kay, L.E. Spectral density function mapping using ${ }^{15} \mathrm{~N}$ relaxation data exclusively. J. Biomol. NMR 1995, 6, 153-162. [CrossRef] [PubMed]

31. Skrisovska, L.; Schubert, M.; Allain, F.H. Recent advances in segmental isotope labeling of proteins: NMR applications to large proteins and glycoproteins. J. Biomol. NMR 2010, 46, 51-65. [CrossRef] [PubMed]

32. Volkmann, G.; Iwai, H. Protein trans-splicing and its use in structural biology: Opportunities and limitations. Mol. Biosyst. 2010, 6, 2110-2121. [CrossRef] [PubMed]

33. Vila-Perello, M.; Muir, T.W. Biological applications of protein splicing. Cell 2010, 143, 191-200. [CrossRef] [PubMed]

34. Evans, T.C., Jr.; Martin, D.; Kolly, R.; Panne, D.; Sun, L.; Ghosh, I.; Chen, L.; Benner, J.; Liu, X.Q.; Xu, M.Q. Protein trans-splicing and cyclization by a naturally split intein from the dnaE gene of Synechocystis species PCC6803. J. Biol. Chem. 2000, 275, 9091-9094. [CrossRef] [PubMed]

35. Scott, C.P.; Abel-Santos, E.; Wall, M.; Wahnon, D.C.; Benkovic, S.J. Production of cyclic peptides and proteins in vivo. Proc. Natl. Acad. Sci. USA 1999, 96, 13638-13643. [CrossRef] [PubMed]

36. Volkmann, G.; Murphy, P.W.; Rowland, E.E.; Cronan, J.E., Jr.; Liu, X.Q.; Blouin, C.; Byers, D.M. Intein-mediated cyclization of bacterial acyl carrier protein stabilizes its folded conformation but does not abolish function. J. Biol. Chem. 2010, 285, 8605-8614. [CrossRef] [PubMed]

37. Buskirk, A.R.; Ong, Y.C.; Gartner, Z.J.; Liu, D.R. Directed evolution of ligand dependence: small-molecule-activated protein splicing. Proc. Natl. Acad. Sci. USA 2004, 101, 10505-10510. [CrossRef] [PubMed]

38. Kanwar, M.; Wright, R.C.; Date, A.; Tullman, J.; Ostermeier, M. Protein switch engineering by domain insertion. Methods Enzymol. 2013, 523, 369-388. [PubMed]

39. Mootz, H.D.; Blum, E.S.; Tyszkiewicz, A.B.; Muir, T.W. Conditional protein splicing: a new tool to control protein structure and function in vitro and in vivo. J. Am. Chem. Soc. 2003, 125, 10561-10569. [CrossRef] [PubMed] 
40. Ozawa, T.; Kaihara, A.; Sato, M.; Tachihara, K.; Umezawa, Y. Split luciferase as an optical probe for detecting protein-protein interactions in mammalian cells based on protein splicing. Anal. Chem. 2001, 73, $2516-2521$. [CrossRef] [PubMed]

41. De Rosa, L.; Russomanno, A.; Romanelli, A.; D'Andrea, L.D. Semi-synthesis of labeled proteins for spectroscopic applications. Molecules 2013, 18, 440-465. [CrossRef] [PubMed]

42. Giriat, I.; Muir, T.W. Protein semi-synthesis in living cells. J. Am. Chem. Soc. 2003, 125, 7180-7181. [CrossRef] [PubMed]

43. Muir, T.W. Studying protein structure and function using semisynthesis. Biopolymers 2008, 90, 743-750. [CrossRef] [PubMed]

44. Buchinger, E.; Aachmann, F.L.; Aranko, A.S.; Valla, S.; Skjak-Braek, G.; Iwai, H.; Wimmer, R. Use of protein trans-splicing to produce active and segmentally ${ }^{2} \mathrm{H},{ }^{15} \mathrm{~N}$ labeled mannuronan C5-epimerase AlgE4. Protein Sci. 2010, 19, 1534-1543. [CrossRef] [PubMed]

45. Busche, A.E.; Aranko, A.S.; Talebzadeh-Farooji, M.; Bernhard, F.; Dotsch, V.; Iwai, H. Segmental isotopic labeling of a central domain in a multidomain protein by protein trans-splicing using only one robust DnaE intein. Angew. Chem. Int. Ed. 2009, 48, 6128-6131. [CrossRef] [PubMed]

46. Muona, M.; Aranko, A.S.; Iwai, H. Segmental isotopic labelling of a multidomain protein by protein ligation by protein trans-splicing. ChemBioChem 2008, 9, 2958-2961. [CrossRef] [PubMed]

47. Otomo, T.; Teruya, K.; Uegaki, K.; Yamazaki, T.; Kyogoku, Y. Improved segmental isotope labeling of proteins and application to a larger protein. J. Biomol. NMR 1999, 14, 105-114. [CrossRef] [PubMed]

48. Yamazaki, T.; Otomo, T.; Oda, N.; Kyogoku, Y.; Uegaki, K.; Ito, N.; Ishino, Y.; Nakamura, H. Segmental isotope labeling for protein NMR using peptide splicing. J. Am. Chem. Soc. 1998, 120, 5591-5592. [CrossRef]

49. Southworth, M.W.; Adam, E.; Panne, D.; Byer, R.; Kautz, R.; Perler, F.B. Control of protein splicing by intein fragment reassembly. EMBO J. 1998, 17, 918-926. [CrossRef] [PubMed]

50. Wu, H.; Hu, Z.; Liu, X.Q. Protein trans-splicing by a split intein encoded in a split DnaE gene of Synechocystis sp. PCC6803. Proc. Natl. Acad. Sci. USA 1998, 95, 9226-9231. [CrossRef] [PubMed]

51. Spyracopoulos, L. A suite of Mathematica notebooks for the analysis of protein main chain ${ }^{15} \mathrm{~N}$ NMR relaxation data. J. Biomol. NMR 2006, 36, 215-224. [CrossRef] [PubMed]

52. Kaderavek, P.; Zapletal, V.; Rabatinova, A.; Krasny, L.; Sklenar, V.; Zidek, L. Spectral density mapping protocols for analysis of molecular motions in disordered proteins. J. Biomol. NMR 2014, 58, 193-207. [CrossRef] [PubMed]

53. Tjandra, N.; Feller, S.E.; Pastor, R.W.; Bax, A. Rotational diffusion anisotropy of human ubiquitin from ${ }^{15} \mathrm{~N}$ NMR relaxation. J. Am. Chem. Soc. 1995, 117, 12562-12566. [CrossRef]

54. Walker, O.; Varadan, R.; Fushman, D. Efficient and accurate determination of the overall rotational diffusion tensor of a molecule from ${ }^{15} \mathrm{~N}$ relaxation data using computer program ROTDIF. J. Magn. Reson. 2004, 168, 336-345. [CrossRef] [PubMed]

55. Ortega, A.; Amoros, D.; Garcia de la Torre, J. Prediction of hydrodynamic and other solution properties of rigid proteins from atomic- and residue-level models. Biophys. J. 2011, 101, 892-898. [CrossRef] [PubMed]

56. Jones, J.A.; Wilkins, D.K.; Smith, L.J.; Dobson, C.M. Characterisation of protein unfolding by NMR diffusion measurements. J. Biomol. NMR 1997, 10, 199-203. [CrossRef]

57. Chaw, R.C.; Zhao, Y.; Wei, J.; Ayoub, N.A.; Allen, R.; Atrushi, K.; Hayashi, C.Y. Intragenic homogenization and multiple copies of prey-wrapping silk genes in Argiope garden spiders. BMC Evol. Biol. 2014. [CrossRef] [PubMed]

58. Cho, C.H.; Urquidi, J.; Singh, S.; Robinson, G.W. Thermal offset viscosities of liquid $\mathrm{H}_{2} \mathrm{O}, \mathrm{D}_{2} \mathrm{O}$, and $\mathrm{T}_{2} \mathrm{O}$. J. Phys. Chem. B 1999, 103, 1991-1994. [CrossRef]

59. Xu, L.; Tremblay, M.L.; Orrell, K.E.; Leclerc, J.; Meng, Q.; Liu, X.Q.; Rainey, J.K. Nanoparticle self-assembly by a highly stable recombinant spider wrapping silk protein subunit. FEBS Lett. 2013, 587, 3273-3280. [CrossRef] [PubMed]

60. Halle, B.; Davidovic, M. Biomolecular hydration: from water dynamics to hydrodynamics. Proc. Natl. Acad. Sci. USA 2003, 100, 12135-12140. [CrossRef] [PubMed]

61. Bae, S.H.; Dyson, H.J.; Wright, P.E. Prediction of the rotational tumbling time for proteins with disordered segments. J. Am. Chem. Soc. 2009, 131, 6814-6821. [CrossRef] [PubMed] 
62. Rezaei-Ghaleh, N.; Klama, F.; Munari, F.; Zweckstetter, M. Predicting the rotational tumbling of dynamic multidomain proteins and supramolecular complexes. Angew. Chem. Int. Ed. 2013, 52, 11410-11414. [CrossRef] [PubMed]

63. Xu, L.; Tremblay, M.L.; Meng, Q.; Liu, X.Q.; Rainey, J.K. ${ }^{1} \mathrm{H},{ }^{13} \mathrm{C}$ and ${ }^{15} \mathrm{~N}$ NMR assignments of the aciniform spidroin (AcSp1) repetitive domain of Argiope trifasciata wrapping silk. Biomol. NMR Assign. 2012, 6, 147-151. [CrossRef] [PubMed]

64. Cantor, C.R.; Schimmel, P.R. Techniques for the study of biological structure and function. In Biophysical Chemistry; W.H. Freeman and Company: San Francisco, CA, USA, 1980; Volume 2, pp. 549-570.

65. Cavanagh, J.; Fairbrother, W.J.; Palmer, A.G., III; Skelton, N.J. Protein NMR Spectroscopy: Principles and Practice; Academic Press: San Diego, CA, USA, 1996; pp. 16-18.

66. Venable, R.M.; Pastor, R.W. Frictional models for stochastic simulations of proteins. Biopolymers 1988, 27, 1001-1014. [CrossRef] [PubMed]

(C) 2016 by the authors; licensee MDPI, Basel, Switzerland. This article is an open access article distributed under the terms and conditions of the Creative Commons Attribution (CC-BY) license (http://creativecommons.org/licenses/by/4.0/). 